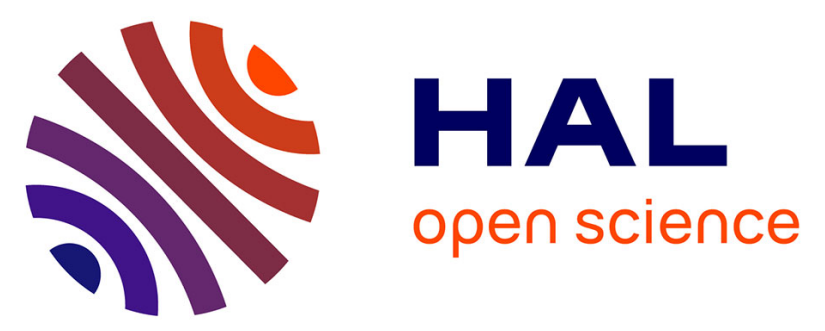

\title{
A theoretical examination of environmental effects on the life cycle schedule and range limits of the invasive seaweed Undaria pinnatifida
}

\author{
James T. Murphy, Mark P. Johnson, Frédérique Viard
}

\section{To cite this version:}

James T. Murphy, Mark P. Johnson, Frédérique Viard. A theoretical examination of environmental effects on the life cycle schedule and range limits of the invasive seaweed Undaria pinnatifida. Biological Invasions, 2017, 19 (2), pp.691-702. 10.1007/s10530-016-1357-1 . hal-01449650

\section{HAL Id: hal-01449650 \\ https://hal.sorbonne-universite.fr/hal-01449650}

Submitted on 30 Jan 2017

HAL is a multi-disciplinary open access archive for the deposit and dissemination of scientific research documents, whether they are published or not. The documents may come from teaching and research institutions in France or abroad, or from public or private research centers.
L'archive ouverte pluridisciplinaire HAL, est destinée au dépôt et à la diffusion de documents scientifiques de niveau recherche, publiés ou non, émanant des établissements d'enseignement et de recherche français ou étrangers, des laboratoires publics ou privés. 
2 A theoretical examination of environmental effects on the life cycle schedule and range 3 limits of the invasive seaweed Undaria pinnatifida

4 James T. Murphy ${ }^{\mathrm{a}, \mathrm{b}^{*}}$, Mark P. Johnson ${ }^{\mathrm{a}}$, Frédérique Viard ${ }^{\mathrm{b}}$

6

aMarine Environment Research Group, Ryan Institute, National University of Ireland Galway, Galway, Ireland.

9 bSorbonne Universités, UPMC Univ Paris 6, CNRS, UMR 7144, Adaptation \& Diversity in Marine Environment department, Divco team, Station Biologique de Roscoff, Place Georges Teissier, 29680 Roscoff, France.

*Corresponding author, mailing address: ${ }^{\text {R}}$ Ryan Institute, National University of Ireland

Galway, Galway, Ireland. Email: jmurphy@sb-roscoff.fr 


\section{Abstract:}

17 Invasive macroalgae form a substantial component of marine invaders at a global level. However, it

18 is poorly understood how the complex interactions between local environmental conditions and life cycle dynamics contribute to invasion success from a mechanistic viewpoint. The aim of this study was to use a model (UndariaGEN) that incorporates a detailed representation of the individual heteromorphic life history stages (sporophytes and gametophytes) of the species in order to explore how interactions between these components contribute to the overall population dynamics. The latest version of the model was validated against field data from a real-life population in Brittany, France. This was followed by an assessment of the role of temperature limitations in determining its potential global range and then a more detailed examination of how environmental factors affect the life cycle dynamics of $U$. pinnatifida across a range of conditions characteristic of European populations. In terms of both relative abundance and recruitment, the model matches closely the patterns observed from field studies in Brittany, France $\left(R^{2}=0.98\right.$ respectively). Furthermore, the model predicted theoretical temperature limits for growth $\left(9.1-22.5^{\circ} \mathrm{C}\right)$ match closely the actual current global range limits for the species $\left(9.5-22.4^{\circ} \mathrm{C}\right)$ reported in the literature. In addition, the size of the species' ecological niche is shown to be directly related to the amplitude in seasonal variation of temperature. This demonstrates that $U$. pinnatifida has a wider ecological niche in conditions of high seasonality; this finding is consistent with theories that propose the heteromorphic life cycle may have evolved as an optimal growth strategy for highly seasonal environments.

Key words: Macroalgae, seaweed, life cycle schedule, individual-based model, agent-based model, ecological niche, species distribution 


\section{Introduction}

Ecological niche models (ENMs) (and related species distribution models, SDMs) are commonly used to predict the potential range limits of invasive species based on their ecological niche characteristics in their native range (Peterson 2003). These approaches can be used to produce accurate habitat suitability maps assuming that ecological niches represent long-term stable constraints on a species' potential geographic range (Marcelino, Verbruggen 2015). Most of these approaches are correlative in nature, by statistically linking spatial environmental data to species distribution records. However, attempts have also been made to incorporate some mechanistic links between the functional traits of organisms and their environments into SDMs (Kearney, Porter 2009). The addition of physiological information can enable more robust predictions of range shifts, particularly in novel or non-equilibrium contexts such as invasions or in response to environmental change, by taking into account niche shifts during biological invasion (Broennimann et al. 2007; Urban et al. 2007).

In this study, an individual-based modelling approach was used to represent the population dynamics of the study species from a bottom-up perspective (DeAngelis, Gross 1992; Grimm, Railsback 2005). This approach means that the individuals of the population are explicitly modelled with individual growth rates and environmental response parameters as opposed to assuming global population averages. This approach allows one to differentiate between the responses of the various life history stages of the species. This is particularly important among species with heteromorphic life cycles consisting of more than one alternating stage or phase. These are characterised by life history stages that often differ in their growth parameters, ecological niches and physical properties (Ebenman 1992; Eckert 2003; Thornber 2006). For example, in the case of many kelp species, the gametophyte and sporophyte stages can differ in their genetic properties (haploid versus diploid), size (microscopic versus macroscopic) and ecophysiology (temperature response profiles, photosynthetic properties) (Morita et al. 2003a, b). For this study, an updated version of an 
individual-based model framework which we previously developed, called UndariaGEN (Murphy et al. 2016a), was used to investigate the population dynamics of the invasive kelp species Undaria pinnatifida in a coastal environment.

Undaria pinnatifida is native to the coastal regions of eastern Asia, including Japan, Korea and China, where it is commonly cultivated for culinary purposes (Ohno, Matsuoka 1993; Shao-jun, Chao-yuan 1996). This edible seaweed was accidentally introduced to Europe in the 1970's in the Étang de Thau, France, followed by deliberate introduction for cultivation purposes in Brittany, France in 1983 (Daguin et al. 2005; Floc'h et al. 1991; Voisin et al. 2005). Subsequent to these introductions it has expanded its range in Europe, invading artificial and natural coastal habitats and extending from southern Italy in the south to the United Kingdom and Ireland in the north (Cecere et al. 2000; Minchin, Nunn 2014; Peteiro 2008). Furthermore, it has also arisen as an invasive threat in other regions of the world such as New Zealand and North America (Hay, Luckens 1987; Silva et al. 2002). Its ability to colonize artificial and disturbed habitats, its high fertility and its fast-growing strategy are among the characteristics that explain its ranking as the third most invasive seaweed, in a species trait analysis of 113 introduced macroalgae, in Europe (Nyberg, Wallentinus 2005).

The annual (or bi-annual) life cycle of $U$. pinnatifida is typical of brown kelp seaweeds with two heteromorphic phases: a microscopic haploid gametophyte stage and a large (1-3 m in length) diploid sporophyte stage (Clayton 1988; Thornber et al. 2004; Wallentinus 2007). These forms differ in their growth requirements and responses to environmental factors such as light and temperature (Morita et al. 2003a, b). The gametophyte stage is likely to facilitate the introduction steps and subsequent spread through ballast water or as epiphytes on ship hulls and oyster shells (Mineur et al. 2007; Mineur et al. 2006). Gametophytes are also capable of delaying their development possibly forming a 'gametophyte bank', analogous to seed banks in terrestrial plants (Carney, Edwards 2006). However, despite their importance in influencing the overall population dynamics at both local and 
regional scales and thus their critical role in invasion success (Couceiro et al. 2013; Edwards 2000), gametophytes are surprisingly hardly considered directly in empirical or theoretical studies.

The aim of this project was to use a model that incorporates a detailed representation of the life history stages of U. pinnatifida with individual gametophytes and sporophytes represented as autonomous agents with independent behaviour. The effects of environmental parameters such as light and temperature on the growth and development of these stages could then be parameterised independently for each stage, using empirical data from the literature, thus allowing population behaviour to be traced back to the individual components. Three seasonally-variable environmental parameters, which have been shown to play a key role in determining the growth potential of $U$. pinnatifida, were examined: light availability, water temperature, and day length (or the photoperiodic effect) (Báez et al. 2010; Campbell et al. 1999; Choi et al. 2007; James et al. 2015; Thornber et al. 2004). There are extensive literature studies on the impact of these abiotic factors on individual growth stages of U. pinnatifida (Choi et al. 2005; Morita et al. 2003a, b; Pang, Lüning 2004; Pang et al. 2008; Shao-jun, Chao-yuan 1996). However, our understanding of the complex spatiotemporal interactions between these factors and the microscopic and macroscopic stages of the life cycle is limited.

\section{Methods}

A detailed description of the underlying model framework and the technical processes involved in its design and parameterisation have been published previously (and presented with updates in Appendix I) (Murphy et al. 2016a). For this study, we upgraded this model and focus on a case study analysis using the model to examine the role of environmental conditions in determining the current range of $U$. pinnatifida in Europe. The model has two measures of invasive potential: (a) 
the traditional measures of population growth (changes in abundance and recruitment over time), and (b) temporal changes to the seasonal schedule of recruitment of the various life history stages. Therefore, in order to factor in these differences between life history stages and between individual sporophytes and gametophytes the IBM approach was chosen. The environment is modelled as a spatially-explicit, discrete two-dimensional grid in order to take into account heterogeneities in the physical surroundings (at a spatial resolution of $0.25 \mathrm{~m}^{2}$ ). Meanwhile, time is represented as discrete time steps with environmental parameters such as temperature and light levels updated on a daily basis. This is to enable seasonal changes in the water conditions to be accounted for and the growth responses of the agents to be updated at a relatively fine-grained scale.

A broad technical overview of the model is included in Appendix I for reference. In the following sections, we highlight the key changes made for the latest version of the model, developed for this study. This upgraded version (v0.6.4) is available under a GNU General Public License Version 3 on the GitHub repository hosting service (https://github.com/murphyjtm/undariaGEN) (Murphy 2016).

\subsection{Sporophyte and gametophyte agents}

The IBM approach involves a bottom-up modelling technique whereby the main components simulated are the individual life history stages, in this case the diploid sporophytes and haploid gametophytes of the U. pinnatifida life cycle. Each individual sporophyte or gametophyte is represented as an independent agent in the model with its own set of unique parameters (e.g. growth rate, temperature response curve, etc.). Individual variability is an important component of an IBM model and therefore a Mersenne Twister random number generator is used to vary the 
growth properties for each individual agent (by sampling from a normal distribution around a population mean) (Matsumoto, Nishimura 1998).

Depending on the type of the agent (sporophyte or gametophyte), the behaviour and responses to local environmental parameters are calculated based on a different set of sub-models, unique to each agent type, which are fitted to ecophysiological data gathered from the literature (see Appendix I). At each time step, the growth rate of each agent is calculated separately according to its type (gametophyte or sporophyte), its own internal state (size, maturity, etc.), and the local environmental conditions (light, temperature, day length) at that point in space and time. The test simulations involved up to $3.0 \times 10^{5}$ agents growing concurrently and independently interacting with their environment and each other. Execution time was approximately 15 minutes per simulated year (on a quad-core Intel Xeon E3 $1270 @ 3.4 \mathrm{GHz}$ desktop computer) The results were then aggregated and population-averaged results, which are an emergent property of all the agents interacting together, were collected for further analysis and presentation.

\subsection{Modification 1: Calculation of photosynthetically available radiation}

In the current and the previous versions of the model, the growth of agents is determined by the availability of light (since they depend on photosynthesis). In the model, there is a parameter for the light attenuation coefficient for photosynthetically available radiation $\left(\mathrm{K}_{\mathrm{dPAR}}\right)$ which determines the amount of light attenuation, with increasing depth in the water column (Saulquin et al. 2013). This is used to calculate the residual energy available for photosynthesis by $U$. pinnatifida agents, depending on their depth, according to the following equation:

$$
E(z)=E(0) e^{-z K_{d P A R}}
$$

where $z$ is the depth $(\mathrm{m})$ of the seaweed below the water surface, $E(0)$ is the level of irradiance at the water surface, and $E(z)$ is the energy available for photosynthesis at depth $z$. For the case studies 
in this paper, the depth $(z)$ was set to $1.0 \mathrm{~m}$ and the attenuation coefficient $\left(\mathrm{K}_{\mathrm{dPAR}}\right)$ to 0.4 for conditions representative of the coastline of Brittany, France (Saulquin et al. 2013).

In the latest version of the model, an additional parameter has been incorporated to represent scale effects on photosynthetic performance between individual plants and communities. It has been demonstrated that the light saturation point $\left(I_{k}\right)$ for macroalgal communities can be several times higher than for individual thallus pieces tested in the laboratory (Binzer, Middelboe 2005). Therefore, in order to make a more realistic representation of natural conditions, we have included an additional parameter to vary the light saturation point according to the community structure. For the test cases described in this paper, this value was calculated by fitting to field data collected from Brest harbour, France (see appendix Table S1). This involved varying the light saturation factor from 1.0 (no competitive inhibition of light) to 10.0 (high saturation point due to complex community structure) and comparing the $\mathrm{R}^{2}$ values. A value of 3.3 resulted in a seasonal pattern of recruitment that most closely matched the natural population in Brest (Fig. 1).

\subsection{Modification 2: Seasonal effects on juvenile mortality among sporophytes}

The death of a sporophyte agent is determined either when it reaches the natural end of its lifespan, assumed to be after it has matured and released all its spores, or through premature death or removal. Field studies have shown that up to $70 \%$ of sporophyte recruits die or are dislodged within one month of their appearance (Voisin 2007). Therefore, premature death (by various means such as competition or physical dislodgement) represents a significant proportion of the deaths in a population. To account for this, field data (Murphy et al. 2016b) collected on a population of $U$. pinnatifida in Brest, France, was used to create an age to mortality curve (Weibull distribution) which determines the probability of premature death as a function of the age of the sporophyte. 
In earlier versions of the model, there was a single age to mortality curve used to describe the probability of premature death among recruits. However, in the latest version, it has been updated to take into account seasonal variation in the probability of mortality (due to changes in competition). For example, in July and August there is a peak in the mortality of young recruits $(<1$ months old), which was not taken into account in the previous version.

Therefore, a series of 12 individual Weibull functions (for each month of the year) were fitted to the mortality data in order to capture the seasonal variation in the probability of premature death. Cosine curves were used to describe the change in the shape $(k)$ and scale $(\lambda)$ parameters of the Weibull curve as a function of the day of the year:

$$
y=A \cos [\omega(x-\alpha)]+C
$$

where $x$ is the day of the year, $A$ is the amplitude, $\alpha$ is the horizontal phase shift, $\mathrm{C}$ is the vertical offset and $\omega$ is the angular frequency $(2 \pi / 365)$. This functional relationship could then be used in the model to generate a probability of premature mortality based on the time of the year and the age of the sporophyte, rather than assuming a constant probability.

\subsection{Validation versus field data from Brest harbour, France}

The updated version of the model was first validated against field data collected from a population of U. pinnatifida growing in Brest harbour, France. The field experiment and raw data are summarized in (Murphy et al. 2016b). This consisted of monthly abundance and recruitment data for the species recorded at Brest harbour, France. Temperature data for the site were sourced from a SOMLIT (Service d'Observation en Milieu Littoral) buoy (INSU-CNRS 2015). Global solar irradiance data (in order to calculate the light availability at the sea surface) were obtained using the CALSOL online application (Institut National de L'Energie Solaire, CEA-CNRS) (INES 2015). Finally, day length 
was calculated based on sunrise/sunset records from the U. S. Naval Observatory's Astronomical Applications Department (USNO 2015).

\subsection{Predicted temperature range of U. pinnatifida}

In order to explore the role of temperature limitations on the potential expansion of $U$. pinnatifida in Europe, a series of simulations to predict the relationship between mean water temperature and annual population growth were carried out. The annual population growth rate is defined as the change in the $(\log )$ total annual recruitment per year. In this case, factors such as competition and space or nutrient limitation were ignored in order to focus on the impact of temperature. A series of simulations (>150) were carried out to predict how the population growth rate changes over a range of temperatures $\left(7.5-23^{\circ} \mathrm{C}\right)$ and different amplitudes in the seasonal variation of the temperature $\left(1-8^{\circ} \mathrm{C}\right)$. This data was used to calculate the temperature ranges for survival of the species, i.e. where the population growth rate is predicted to be greater than zero.

\subsection{Case studies: Effect of environmental conditions on life cycle schedule}

Following the high level analysis, a number of case study simulations were carried out to explore the effects of environmental conditions on the life cycle schedule of the species. Three test case scenarios ("North", "Central", and "South") were proposed that represent a range of environmental conditions to which populations may be exposed along a latitudinal gradient in Europe. These test cases are characterised by differences in the temperature, irradiance and day length regimes. All other parameters are maintained constant (e.g. biotic parameters of the algae, and other factors such as depth, light attenuation factor etc.). See Table 1 for a comparison of the environmental input parameters that were varied between the three test case scenarios. 

representative of the northern edge of U. pinnatifida's current reported range in Europe (Northern Ireland). This test case is characterised by a relatively low mean water temperature $\left(11.2^{\circ} \mathrm{C}\right)$ and light availability (9.1 $\mathrm{MJ} \mathrm{m}^{-2}$ day $\left.^{-1}\right)$, as well as strong seasonal variation in day length due to the latitudinal location $\left(54.6^{\circ} \mathrm{N}\right)$. An alternative scenario, representative of the southern range limits of $U$. pinnatifida, was also analysed (referred to as "South"). This represents conditions of relatively high water temperature $\left(19.8^{\circ} \mathrm{C}\right)$, high light availability $\left(15.1 \mathrm{MJ} \mathrm{m}^{-2} \mathrm{day}^{-1}\right)$ and lower seasonal variation in day length (latitude $=42.5^{\circ} \mathrm{N}$ ). These latter conditions are similar to those present towards the southern limit of U. pinnatifida's current range in Europe (Ionian Sea, southern Italy) (Cecere et al. 2000). As a control, the results from the simulation of Brest harbour are included, referred to as "Central" since it is approximately in the middle of the species' current range distribution in Europe along the North-South gradient. Brittany is also representative of the biogeographic transition between Lusitanian and Boreal Province in the NE Atlantic (Spalding et al. 2007). This test case represents an intermediate scenario in terms of water temperature $\left(13.3^{\circ} \mathrm{C}\right)$, light availability $(11.4$ $\mathrm{MJ} \mathrm{m} \mathrm{m}^{-2}$ day $^{-1}$ ) and day length (latitude $=48.4^{\circ} \mathrm{N}$ ).

\section{Results}

\subsection{Validation versus field data from Brest harbour, France}

The predicted relative monthly abundance and recruitment data for sporophytes of $U$. pinnatifida were compared to field data from Brest harbour, France (Fig. 1). In terms of both relative abundance (total number of sporophytes) and recruitment (number of newly recruited sporophytes, $>5 \mathrm{~cm}$ in length) the model matches closely the patterns observed in the real life population $\left(R^{2}=0.98\right.$ respectively). It also shows good quantitative agreement with field data in terms of age to maturity 
The results of validating the model versus field data show a substantial improvement in the

250

251

252

253

254

255

256

257

258

259

260

261

262

263

264

265

266

267

268

269

270

271

272

accuracy of predictions compared to the previously published version of the model: $R^{2}$ values increased from 0.84 to 0.98 and 0.85 to 0.98 for abundance and recruitment respectively (Murphy et al. 2016a). This result suggests that the majority (84\%) of monthly variation in abundance of $U$. pinnatifida sporophytes can be explained by seasonal changes in environmental parameters (light, temperature and photoperiodic effect). However, increased juvenile mortality in the summer could be due to competitive interactions and community effects potentially offsetting the effects of high recruitment.

\subsection{Predicted temperature range of U. pinnatifida}

Globally, U. pinnatifida has been found in areas with mean water temperatures (seasonal range between min and max included in brackets) as low as $9.5^{\circ} \mathrm{C}\left(6.0-13.0^{\circ} \mathrm{C}\right.$, in Southern Patagonia, Argentina, Lat. -47.75 Long. -65.92$)$ and as high as $22.4^{\circ} \mathrm{C}\left(16.8-28.0^{\circ} \mathrm{C}\right.$, in its native range of Japan, Lat. 31.85 Long. 130.15) (Dellatorre et al. 2014; Martin, Cuevas 2006; Saito 1975). When simulations were carried out with seasonal temperature conditions representative of these regions (amplitude $=3.5^{\circ} \mathrm{C}$ in Southern Patagonia, and $5.5^{\circ} \mathrm{C}$ in southern Japan), the model predicted temperature limits for growth were $9.1^{\circ} \mathrm{C}\left(5.6-12.6^{\circ} \mathrm{C}\right)$ and $22.5^{\circ} \mathrm{C}\left(17-28^{\circ} \mathrm{C}\right)$ respectively, which closely matches the actual range limits $\left(9.5 \& 22.4^{\circ} \mathrm{C}\right)$ above (Fig $\left.4 \mathrm{a}\right)$. In addition to the mean annual water temperature, the effect of the amplitude of the seasonal change in water temperature (between the warmest and coolest months of the year) was explored in more depth. The results indicate that the theoretical thermal niche of $U$. pinnatifida increases as a function of the amplitude of the seasonal change in temperature (Fig. 3b). 

the three case study populations (Fig. 4). For example, the northern population is predicted to peak in abundance later in the year (April) compared to the southern population (March) (Fig 5a), and has lower overall recruitment compared to both the central and southern populations (Fig 5b). There are also distinct differences in the seasonal growth rates of the individual sporophyte and gametophyte agents (Fig. 5). In general, the populations further south are predicted to reach optimal growth rates earlier in the spring, before temperature becomes a limiting factor. Furthermore, individuals in the south have a shorter predicted lifespan since they reach maturity and release their spores earlier in the year (Fig. 2b) due to spore release triggered by warming temperatures (Suto 1952). formation of a new generation of sporophytes) was compared across the three locations (Fig. 6). For the central and northern populations, there are two clear annual peaks in the fertility of gametophytes, in October and February respectively. However, the southern population lacks the autumn peak due to inhibition of gametogenesis and therefore has a narrower window of opportunity for forming a new generation of sporophytes. This also explains the characteristic pattern of recruitment observed in Figure $4 \mathrm{~b}$ where the southern population lacked a secondary minor peak in recruitment in late November.

\section{Discussion}

The close agreement between the predicted abundance and recruitment values with field data for sporophytes growing in Brittany, France (Fig. 1) is particularly interesting in light of the diverse sources of input data used to parameterise the model. For the most part, the ecophysiological data used to parameterise the model came from individuals sampled in the study 
populations). For example, the temperature response curves for the gametophytes and sporophytes came from individuals sampled in Japan (Morita et al. 2003a, b). Similarly, the effects of light and day length on gametophyte growth and reproduction were based on studies in the Korean peninsula (Choi et al. 2005). Finally, photosynthesis-irradiance curves for the sporophytes were sourced from studies in south-eastern Australia (Campbell et al. 1999).

Therefore, it is noteworthy that the model predicts a pattern of monthly recruitment and abundance that closely matches the patterns observed among a population growing in western France $\left(R^{2}=0.98\right)$. This suggests potentially strong phenotypic conservation in terms of its response to environmental factors since the species' introduction to Brittany, France over 40 years ago. This may be explained by a large physiological niche for U. pinnatifida. Broad physiological tolerance is an important component of invasiveness in terrestrial plants (Higgins, Richardson 2014). But there are currently no similar studies available for macroalgae, and a lack of experimental data on the basic physiological responses of $U$. pinnatifida populations in Europe compared to those in its native range.

Similarly, the model predicted temperature limits match closely with the current known global distribution for $U$. pinnatifida when taking into account both the mean water temperature and the amplitude of seasonal variation (Fig. 3a). In particular, the size of the species' ecological niche is shown to be directly related to the amplitude in seasonal variation of temperature (Fig. $3 \mathrm{~b}$ ). This demonstrates that U. pinnatifida has a wider ecological niche in conditions of high seasonality, and is consistent with theories that propose the heteromorphic life cycle, characteristic of species such as this, may have evolved as an optimal growth strategy for highly seasonal environments (Bessho, Iwasa 2009).

However, there are a number of other indirect effects which must be taken into account when determining the theoretical range limits of U. pinnatifida, for example how changes in the seasonal pattern and timing of recruitment might affect its competitive ability versus native species. 
322 These changes can affect its ability to invade natural habitats, even when the temperature conditions are suitable for recruitment. For example, James et al. (2015) discussed how seasonal changes to phenology may affect impacts from invasion. To explore this, a number of test cases scenarios were designed to represent the conditions populations are exposed to at the current northern and southern range limits of U. pinnatifida in Europe. the fundamental growth rates of the $U$. pinnatifida agents in response to the environmental parameters. The predicted growth rates of both the gametophyte and sporophyte stages of the life cycle are limited by sub-optimal temperature and irradiance conditions in the north (Fig. 5). There is also a delay in the shedding of spores due to inhibition under cooler water conditions in early summer which may explain the delayed pattern of recruitment in the northern population $\left(<12^{\circ} \mathrm{C}\right)$ (Suto 1952). However, there is another notable feature in the predicted recruitment, for both the Central and Northern populations, evident in Figure $4 \mathrm{~b}$. That is the presence of a minor secondary recruitment peak in November, in addition to the primary spring peak in April. This secondary annual peak in recruitment is absent from the predicted results for the southern population. surveyed in Brest harbour (Fig. 1b) and in populations introduced in other temperate regions where temperatures vary annually between 10 and $21^{\circ} \mathrm{C}$ ( $\mathrm{N}$ America; Thornber et al. 2004). This pattern of recruitment can be explained by differences in the seasonal patterns of gametogenesis (Fig. 6). The model predicts a delay of several months in the onset of maturity among $U$. pinnatifida gametophytes on the southern range edge. This results in a substantial change in the seasonal pattern of gametogenesis that, if exhibited in natural populations, could significantly impact their life cycle schedule and affect their potential for establishment in lower latitudes. U. pinnatifida is considered an opportunistic and pioneering species and the ability to recruit earlier in the year is thought to confer on it a competitive advantage compared to native macroalgal species in Brittany, 
France (Grulois et al. 2011). However, in the Mediterranean Sea, a delay in gametogenesis could play a critical role in limiting the ability of $U$. pinnatifida to supplant native species from their ecological niche.

Indeed, although the first reported occurrence of U. pinnatifida in Europe occurred in Étang de Thau, on the Mediterranean coast of France in the 1970's, it has failed to establish itself in the surrounding region subsequently (Floc'h et al. 1991). It is still present in Thau lagoon but only in a small number of discrete locations and it has not expanded outside the lagoon (F. Viard, pers. obs.). Potential explanations for this have included nutrient limitations due to the oligotrophic nature of this region of the Mediterranean Sea (Báez et al. 2010). Indeed, populations have been found in nutrient-rich polluted waters in the Venice lagoon and the lonian Sea off southern Italy (Cecere et al. 2000; Curiel et al. 1998; Curiel et al. 2002). Other factors such as chlorophyll concentration and shading have also been shown to be important for the growth of the species (Báez et al. 2010).

The results in the current study represent a potential alternative explanation, for the lack of expansion in Mediterranean populations, through disturbance to the life cycle schedule of the species. A delay of a few months in the predicted onset of gametogenesis under the warmer southern conditions could be a critical factor in reducing the population's ability to settle and establish itself opportunistically in the natural habitat. This also agrees with theoretical studies that have indicated macroalgal species with heteromorphic life cycles, such as U. pinnatifida, may be better adapted to the more strongly seasonal environments of northern latitudes (Bessho, Iwasa 2009). This could limit the species competitive ability to establish itself in lower latitudes even in cases where nutrient limitation is not a factor.

With regard to the northern range limits of $U$. pinnatifida in Europe, currently the most northerly reported population is in Northern Ireland where mean annual water temperatures are approximately $11-12^{\circ} \mathrm{C}$ (Minchin, Nunn 2014). This is within the tolerance limit for the sustainability of a population according to the model predictions (Fig. 3). This also agrees with other studies, using 
habitat suitability models, which have indicated that temperature may not be a limiting factor for its distribution in the British Isles (Yesson et al. 2015). In terms of gametogenesis, populations are also predicted to maintain the characteristic bi-annual peak in gametophyte fertility (Fig. 5). This means that it also has the potential to be an opportunistic invader through early recruitment.

Therefore, under this model, the environmental conditions are predicted to be suitable for the continued spread of the species as an invasive threat in the British Isles, particularly under scenarios of increasing sea water temperatures (Mackenzie, Schiedek 2007). However, expansion to waters with a mean annual temperature $<10^{\circ} \mathrm{C}$ will depend on the seasonal variation in the temperature. When the seasonal amplitude in water temperature is $\left\langle 3.5^{\circ} \mathrm{C}\right.$, then the minimum temperature a population is predicted to survive in is $>9.1^{\circ} \mathrm{C}$ (Fig. 3a). However, in the case of a high variation between summer and winter temperatures (amplitude $5.5^{\circ} \mathrm{C}$ ), it is possible that populations of $U$. pinnatifida could survive in conditions where the mean annual temperature is as low as $8^{\circ} \mathrm{C}$. In this case, other factors such as light or nutrient availability might become more important limiting factors.

These model results indicate that both direct and indirect effects on the life cycle schedule may determine the future expansion potential of $U$. pinnatifida in Europe and elsewhere. These types of subtle interactions are not as readily apparent when considering the invasion from a population perspective only. This modelling approach represents a promising framework that could be applied to other species of macroalgae with heteromorphic life histories in order to understand better their growth and life cycle dynamics and how these contribute to their potential distribution range under variable climatic conditions.

Future work will require a detailed analysis of the role of other factors such as nutrient limitations and biotic interactions versus direct and indirect effects of environmental factors on the life cycle schedule of $U$. pinnatifida in order to build a complete picture of the invasion dynamics. This model is somewhat limited in that it focuses on seasonal changes in light, temperature and day 
length only. Nevertheless, the results raise interesting points about the role of changes in the life cycle schedule and seasonal cycle on the invasive potential of species such as $U$. pinnatifida. Potential temporal changes in the life cycle schedule of introduced species outside their native range can have important impacts when it comes to accurately predicting their range limits and should be considered in future modelling studies.

\section{Acknowledgements}

This research is supported by an Irish Research Council ELEVATE international career development fellowship, co-funded by Marie Curie Actions under the European Union's Seventh Framework Programme. The field data presented here, which were collected in Brest, were obtained as part of the PhD thesis of Marie Voisin who benefitted from a Ph.D. fellowship ("Renouvellement des Compétences" Program) from the Region Bretagne. MV and FV are thankful to the many people from the Department AD2M of the Station Biologique de Roscoff who provided help for the surveys carried out in the field.

\section{References}

Báez JC, Olivero J, Peteiro C, et al. (2010) Macro-environmental modelling of the current distribution of Undaria pinnatifida (Laminariales, Ochrophyta) in northern Iberia. Biological Invasions 12:2131-2139

Bessho K, Iwasa Y (2009) Heteromorphic and isomorphic alternations of generations in macroalgae as adaptations to a seasonal environment. Evolutionary Ecology Research 11:691-711

Binzer T, Middelboe AL (2005) From thallus to communities: scale effects and photosynthetic performance in macroalgae communities. Marine Ecology Progress Series 287:65-75

Broennimann O, Treier UA, Müller-Schärer H, et al. (2007) Evidence of climatic niche shift during biological invasion. Ecology Letters 10:701-709

Campbell SJ, Bité JS, Burridge TR (1999) Seasonal Patterns in the Photosynthetic Capacity, Tissue Pigment and Nutrient Content of Different Developmental Stages of Undaria pinnatifida (Phaeophyta: Laminariales) in Port Phillip Bay, South-Eastern Australia. Botanica Marina 42:231 
Carney LT, Edwards MS (2006) Cryptic Processes in the Sea: A Review of Delayed Development in the Microscopic Life Stages of Marine Macroalgae. Algae 21:161-168

Cecere E, Petrocelli A, Daniela Saracino O (2000) Undaria pinnatifida (Fucophyceae, Laminariales) spread in the central Mediterranean: Its occurrence in the Mar Piccolo of Taranto (Ionian Sea, southern Italy). Cryptogamie Algologie 21:305-309

Choi H, Kim Y, Lee S, et al. (2007) Growth and reproductive patterns of Undaria pinnatifida sporophytes in a cultivation farm in Busan, Korea. J Appl Phycol 19:131-138

Choi H, Kim Y, Lee S, et al. (2005) Effects of daylength, irradiance and settlement density on the growth and reproduction of Undaria pinnatifida gametophytes. J Appl Phycol 17:423-430

Clayton MN (1988) Evolution and Life Histories of Brown Algae. Botanica Marina 31:379

Couceiro L, Peters A, Le Gac M, et al. (2013) The Ectocarpus life cycle in the field supports the hypothesis of niche separation between gametophytes and sporophytes. Phycologia 52:20-21

Curiel D, Bellemo G, Marzocchi M, et al. (1998) Distribution of introduced Japanese macroalgae Undaria pinnatifida, Sargassum muticum (Phaeophyta) and Antithamnion Pectinatum (Rhodophyta) in the Lagoon of Venice. Hydrobiologia 385:17-22

Curiel D, Guidetti P, Bellemo G, et al. (2002) The introduced alga Undaria pinnatifida (Laminariales, Alariaceae) in the lagoon of Venice. Hydrobiologia 477:209-219

Daguin C, Voisin M, Engel C, et al. (2005) Microsatellites isolation and polymorphism in introduced populations of the cultivated seaweed Undaria pinnatifida (Phaeophyceae, Laminariales). Conserv Genet 6:647-650

DeAngelis DL, Gross LJ (1992) Individual-based models and approaches in ecology: populations, communities and ecosystems. Chapman \& Hall

Dellatorre FG, Amoroso R, Saravia J, et al. (2014) Rapid expansion and potential range of the invasive kelp Undaria pinnatifida in the Southwest Atlantic. Aquatic Invasions 9:467-478

Ebenman B (1992) Evolution in organisms that change their niches during the life-cycle. Am. Nat. 139:990-1021

Eckert GL (2003) Effects of the planktonic period on marine population fluctuations. Ecology 84:372383

Edwards MS (2000) The Role of Alternate Life-History Stages of a Marine Macroalga: A Seed Bank Analogue. Ecology 81:2404-2415

Floc'h JY, Pajot R, Wallentinus I (1991) The Japanese brown alga Undaria pinnatifida on the coast of France and its possible establishment in European waters. Journal du Conseil: ICES Journal of Marine Science 47:379-390

Grimm V, Railsback SF (2005) Individual-based Modeling and Ecology. Princeton University Press

Grulois D, Lévêque L, Viard F, et al. (2011) Mosaic genetic structure and sustainable establishment of the invasive kelp Undaria pinnatifida within a bay (Bay of St-Malo, Brittany). CBM-Cahiers de Biologie Marine 52:485

Hay CH, Luckens PA (1987) The Asian kelp Undaria pinnatifida (Phaeophyta: Laminariales) found in a New Zealand harbour. New Zealand Journal of Botany 25:329-332

Higgins SI, Richardson DM (2014) Invasive plants have broader physiological niches. Proceedings of the National Academy of Sciences of the United States of America 111:10610-10614

INES (2015) Logiciel CALSOL. Institut National de L'Energie Solaire, France,

INSU-CNRS (2015) SOMLIT - Service d'Observation en Milieu Littoral. Institut National des Sciences de I'Univers (CNRS), France,

James K, Kibele J, Shears N (2015) Using satellite-derived sea surface temperature to predict the potential global range and phenology of the invasive kelp Undaria pinnatifida. Biological Invasions 17:3393-3408

Kearney M, Porter W (2009) Mechanistic niche modelling: combining physiological and spatial data to predict species' ranges. Ecology Letters 12:334-350

Mackenzie BR, Schiedek D (2007) Daily ocean monitoring since the 1860 s shows record warming of northern European seas. Global Change Biology 13:1335-1347 
Marcelino VR, Verbruggen H (2015) Ecological niche models of invasive seaweeds. Journal of Phycology 51:606-620

Martin JP, Cuevas JM (2006) First Record of Undaria Pinnatifida (Laminariales, Phaeophyta) in Southern Patagonia, Argentina. Biological Invasions 8:1399-1402

Matsumoto M, Nishimura T (1998) Mersenne twister: a 623-dimensionally equidistributed uniform pseudo-random number generator. ACM Trans. Model. Comput. Simul. 8:3-30

Minchin D, Nunn J (2014) The invasive brown alga Undaria pinnatifida (Harvey) Suringar, 1873 (Laminariales: Alariaceae), spreads northwards in Europe. Biolnvasions Records 3:57-63

Mineur F, Belsher T, Johnson MP, et al. (2007) Experimental assessment of oyster transfers as a vector for macroalgal introductions. Biological Conservation 137:237-247

Mineur F, Johnson MP, Maggs CA, et al. (2006) Hull fouling on commercial ships as a vector of macroalgal introduction. Marine Biology 151:1299-1307

Morita T, Kurashima A, Maegawa M (2003a) Temperature requirements for the growth and maturation of the gametophytes of Undaria pinnatifida and $U$. undarioides (Laminariales, Phaeophyceae). Phycological Research 51:154-160

Morita T, Kurashima A, Maegawa M (2003b) Temperature requirements for the growth of young sporophytes of Undaria pinnatifida and Undaria undarioides (Laminariales, Phaeophyceae). Phycological Research 51:266-270

Murphy JT (2016) UndariaGEN - A spatially-explicit agent-based model of macroalgae in the marine environment. https://github.com/murphyitm/undariaGEN

Murphy JT, Johnson MP, Viard F (2016a) A modelling approach to explore the critical environmental parameters influencing the growth and establishment of the invasive seaweed Undaria pinnatifida in Europe. J Theor Biol 396:105-115

Murphy JT, Voisin M, Johnson M, et al. (2016b) Abundance and recruitment data for Undaria pinnatifida in Brest harbour, France: Model versus field results. Data in Brief 7:540-5

Nyberg C, Wallentinus I (2005) Can species traits be used to predict marine macroalgal introductions? Biological Invasions 7:265-279

Ohno M, Matsuoka M (1993) Undaria cultivation 'wakame'. Seaweed cultivation and marine ranching. Kanagawa International Fisheries Training Center Japan International Cooperative Agency, Yokosuka:41-49

Pang S, Lüning K (2004) Photoperiodic long-day control of sporophyll and hair formation in the brown alga Undaria pinnatifida. J Appl Phycol 16:83-92

Pang SJ, Shan TF, Zhang ZH (2008) Responses of vegetative gametophytes of Undaria pinnatifida to high irradiance in the process of gametogenesis. Phycological Research 56:280-287

Peteiro C (2008) A new record of the introduced seaweed Undaria pinnatifida (Laminariales, Phaeophyceae) from the Cantabrian Sea (northern Spain) with comments on its establishment. Aquatic Invasions 3:413-415

Peterson AT (2003) Predicting the Geography of Species' Invasions via Ecological Niche Modeling. The Quarterly Review of Biology 78:419-433

Saito $Y$ (1975) Undaria. Advance of Phycology in Japan, Junk Publishers, The Hague:304-320

Saulquin B, Hamdi A, Gohin F, et al. (2013) Estimation of the diffuse attenuation coefficient KdPAR using MERIS and application to seabed habitat mapping. Remote Sensing of Environment 128:224-233

Shao-jun P, Chao-yuan W (1996) Study on gametophyte vegetative growth of Undaria pinnatifida and its applications. Chin J Oceanol Limn 14:205-210

Silva P, Woodfield R, Cohen A, et al. (2002) First Report of the Asian kelp Undaria pinnatifida in the Northeastern Pacific Ocean. Biological Invasions 4:333-338

Spalding MD, Fox HE, Allen GR, et al. (2007) Marine Ecoregions of the World: A Bioregionalization of Coastal and Shelf Areas. BioScience 57:573-583

Suto $S$ (1952) On shedding of zoospores in some algae of Laminariaceae-2. Bulletin of the Japanese Society of Scientific Fisheries 18:1-5 
Thornber CS (2006) Functional properties of the isomorphic biphasic algal life cycle. Integrative and Comparative Biology 46:605-614

Thornber CS, Kinlan BP, Graham MH, et al. (2004) Population ecology of the invasive kelp Undaria pinnatifida in California: environmental and biological controls on demography. Marine Ecology Progress Series 268:69-80

Urban MC, Phillips BL, Skelly DK, et al. (2007) The cane toad's (Chaunus [Bufo] marinus) increasing ability to invade Australia is revealed by a dynamically updated range model. Proc. R. Soc. Lond., B, Biol. Sci. 274:1413-1419

USNO (2015) Table of sunrise/sunset for an entire year. US Naval Observatory Astronomical Applications Department, Washington DC,

Voisin M (2007) Les processus d'invasions biologiques en milieu côtier marin: le cas de l'algue brune Undaria pinnatifida, cultivée et introduite à l'échelle mondiale (PhD diss.). Paris 6, France,

Voisin M, Engel CR, Viard F (2005) Differential shuffling of native genetic diversity across introduced regions in a brown alga: Aquaculture vs. maritime traffic effects. Proceedings of the National Academy of Sciences of the United States of America 102:5432-5437

Wallentinus I (2007) Alien Species Alert: Undaria pinnatifida (wakame or Japanese kelp). ICES Cooperative Research Report,

Yesson C, Bush LE, Davies AJ, et al. (2015) The distribution and environmental requirements of large brown seaweeds in the British Isles. Journal of the Marine Biological Association of the United Kingdom 95:669-680 
550 Table 1: Environmental input parameters for three locations representing the current known

551 geographic range of Undaria pinnatifida in European coastal waters. North = Northern Ireland;

552 Central = Brittany (Brest Harbour), France; South = Mediterranean Sea (Taranto, Italy). Global solar

553 irradiance data from CALSOL online application (Institut National de L'Energie Solaire, CEA-CNRS)

554 (INES 2015). Day length calculated based on sunrise/sunset records from the U.S. Naval

555 Observatory's Astronomical Applications Department (USNO 2015). Temperature data: Met Eireann

556 (Irish National Meteorological Service), SOMLIT (Service d'Observation en Milieu Littoral, INSU-

557 CNRS), Dellatorre et al. (2014).

\begin{tabular}{|c|c|c|c|c|c|c|c|}
\hline \multirow[t]{2}{*}{ Location } & \multirow[t]{2}{*}{$\begin{array}{l}\text { Latitude } \\
\text { (Degrees N) }\end{array}$} & \multicolumn{2}{|c|}{ Temperature $\left({ }^{\circ} \mathrm{C}\right)$} & \multicolumn{2}{|c|}{$\begin{array}{c}\text { Irradiance } \\
\left(\mathrm{MJ} \mathrm{m}^{-2} \text { day }^{-1}\right)\end{array}$} & \multicolumn{2}{|c|}{ Day Length (h) } \\
\hline & & Mean & Amplitude & Mean & Amplitude & Mean & Amplitude \\
\hline North & 59.6 & 11.17 & 3.26 & 9.1 & 8.65 & 12.3 & 4.82 \\
\hline Central & 48.4 & 13.33 & 4.14 & 11.36 & 9.05 & 12.3 & 3.77 \\
\hline South & 40.4 & 19.8 & 6.3 & 15.1 & 8.8 & 12.2 & 3 \\
\hline
\end{tabular}


List of Figures:

560

(a)

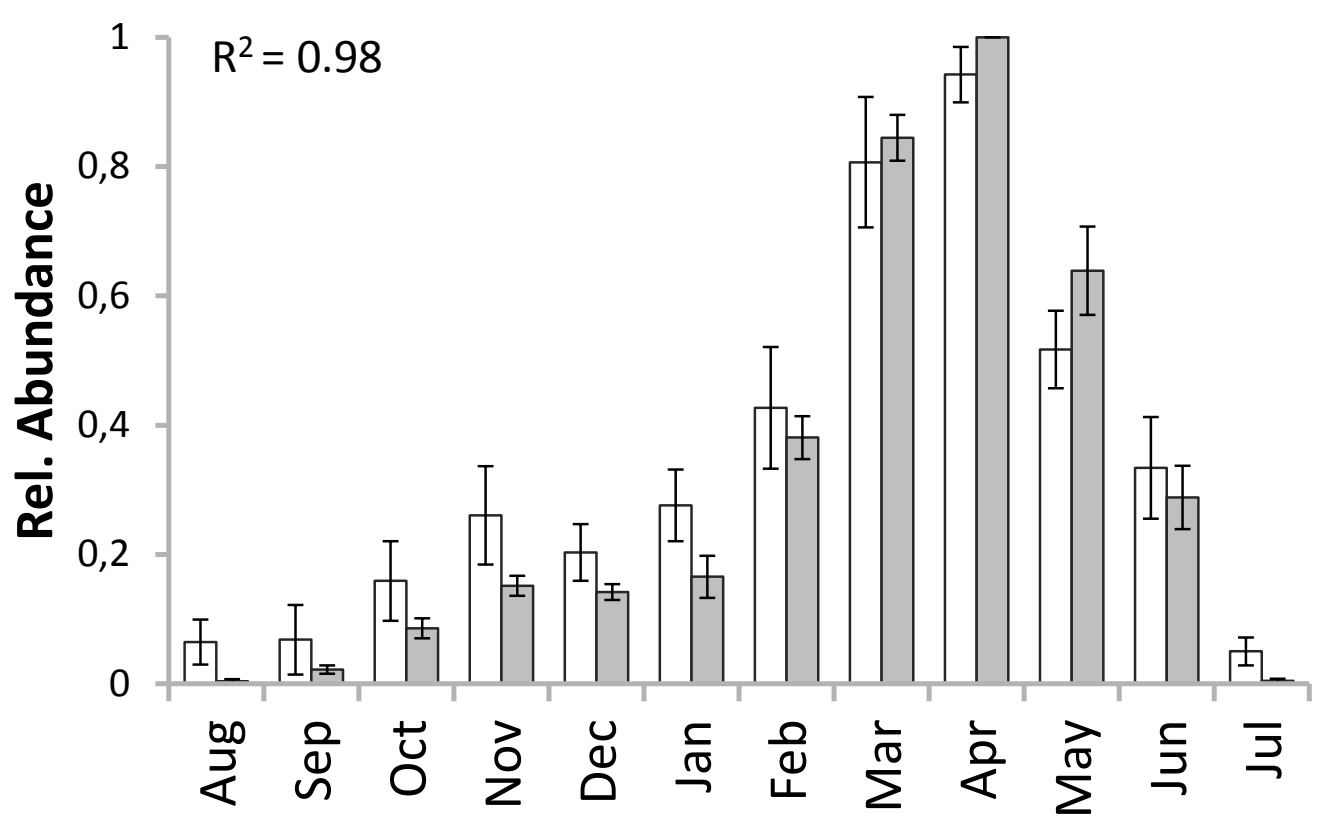

561

562

(b)

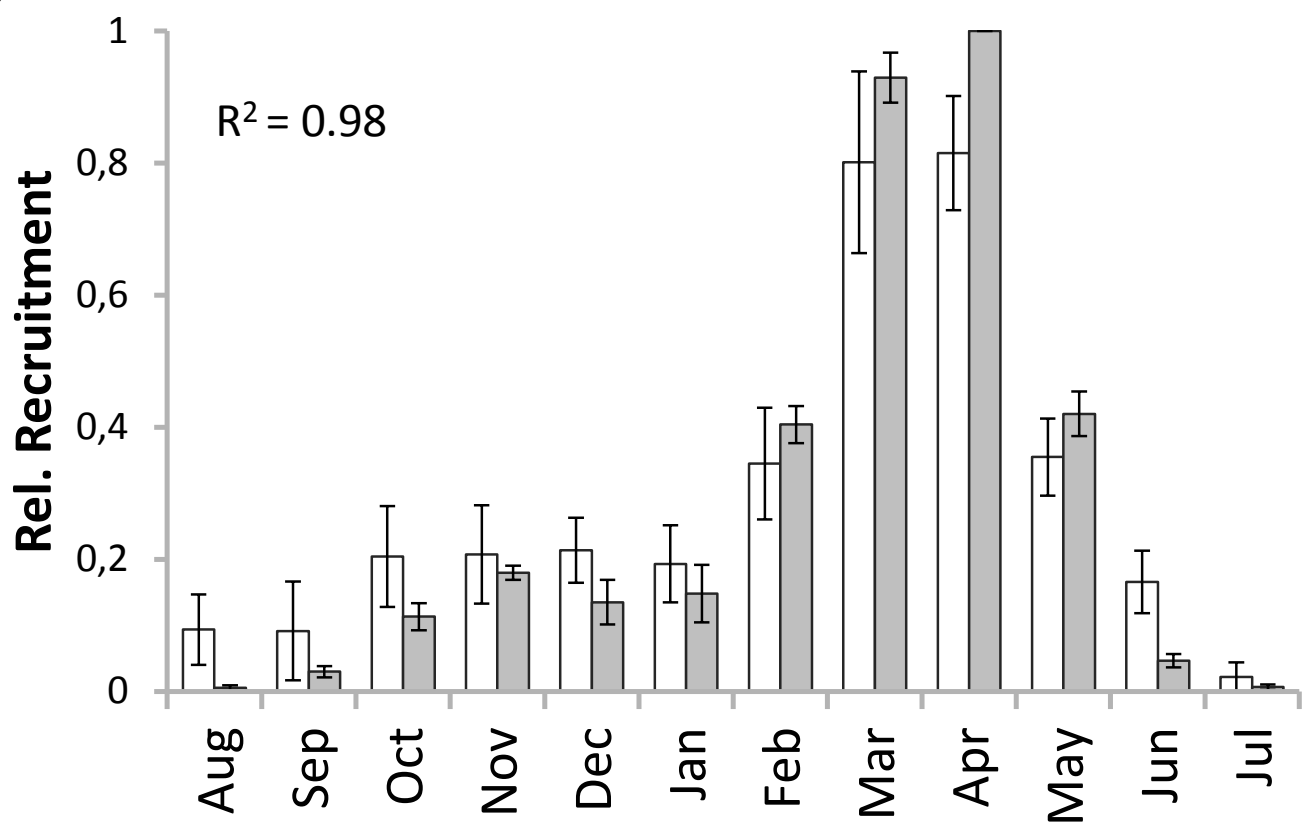

$\square$ Field Data $\square$ Predicted

564 Fig. 1: Model predicted values for (a) relative abundance and (b) relative recruitment of an $U$. pinnatifida population in a simulated harbour environment versus field data from Brest harbour in Brittany, France (Voisin, 2007). Predicted values represent mean ( \pm S.D.) from four simulated years. 
(a)
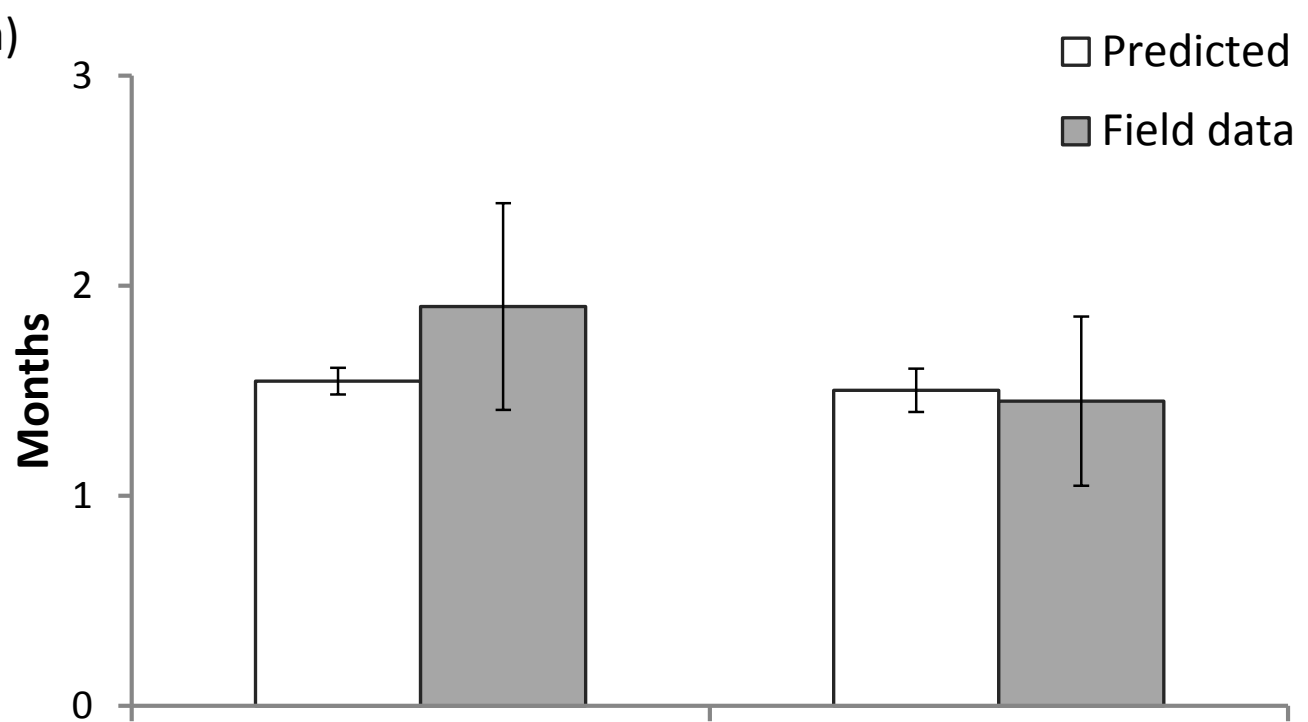

Age at Maturity Months Mature

(b)

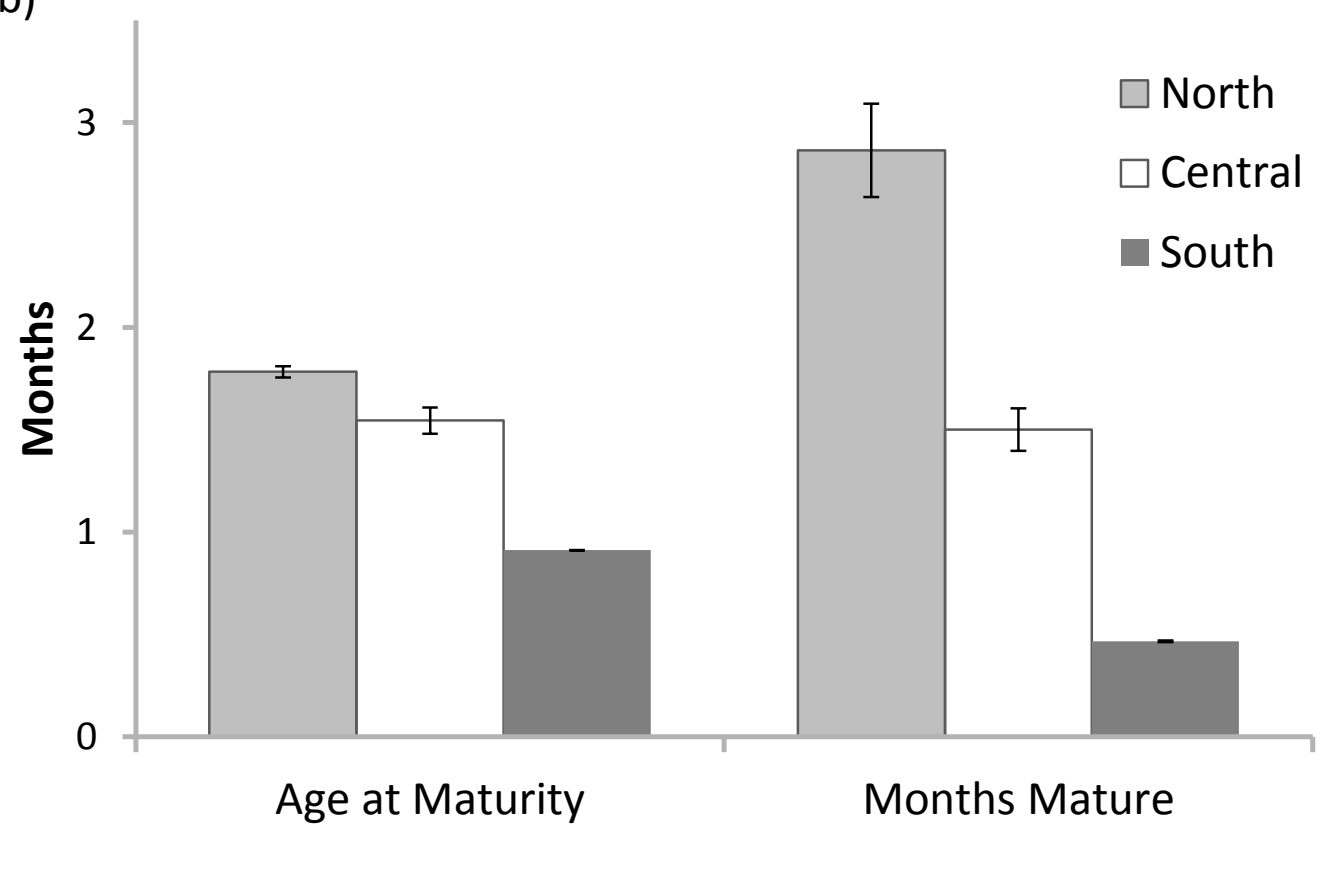

Fig. 2: (a) Predicted age to maturity and months mature for $U$. pinnatifida sporophytes compared to field data from Brest harbour, France. (b) Predicted age to maturity and months mature for populations of $U$. pinnatifida sporophytes under the three test case scenarios. North $=\mathrm{N}$. Ireland; Central $=$ Brest harbour, France; South = Mediterranean Sea (Taranto, Italy). 


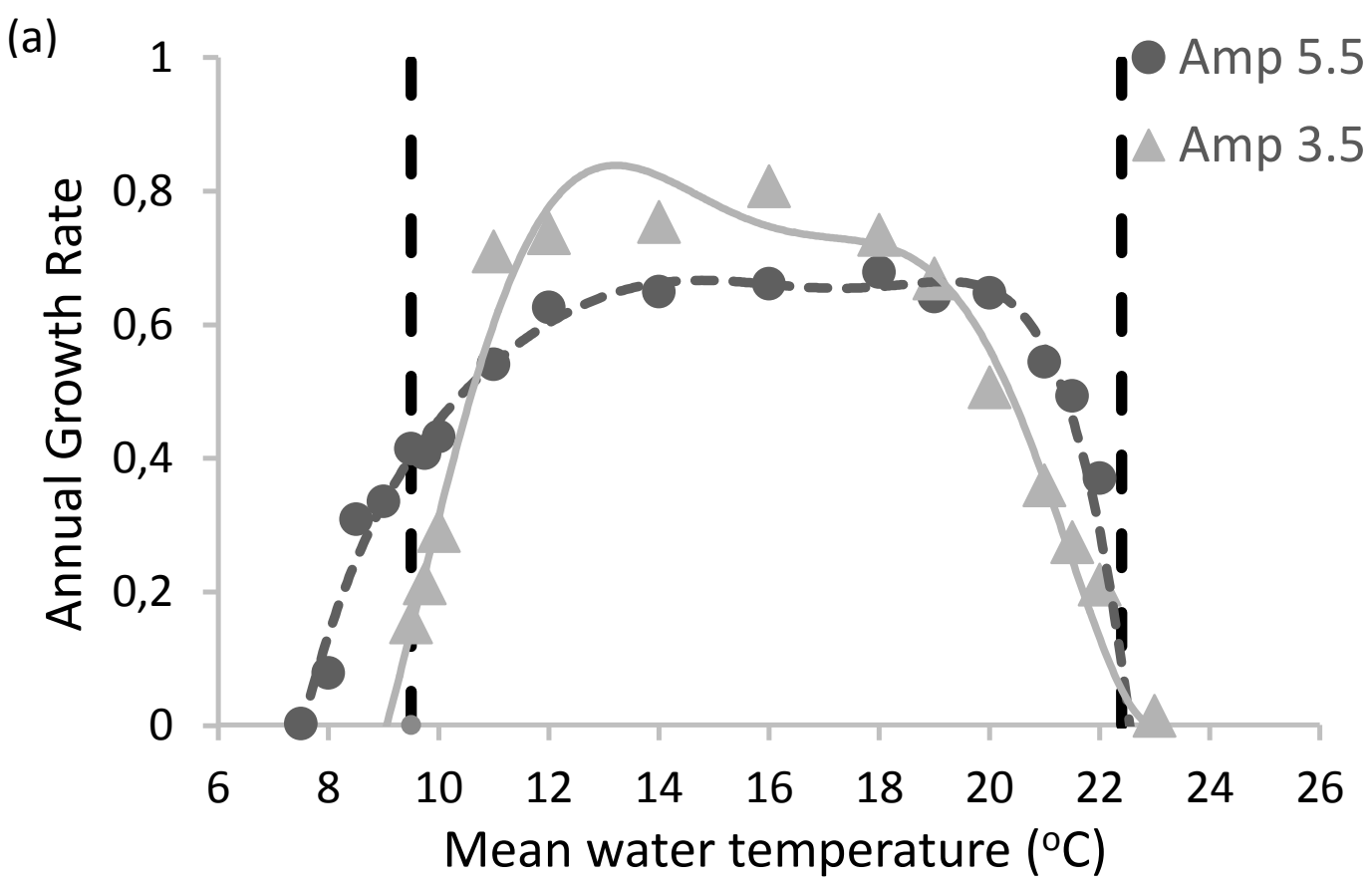

576

(b)

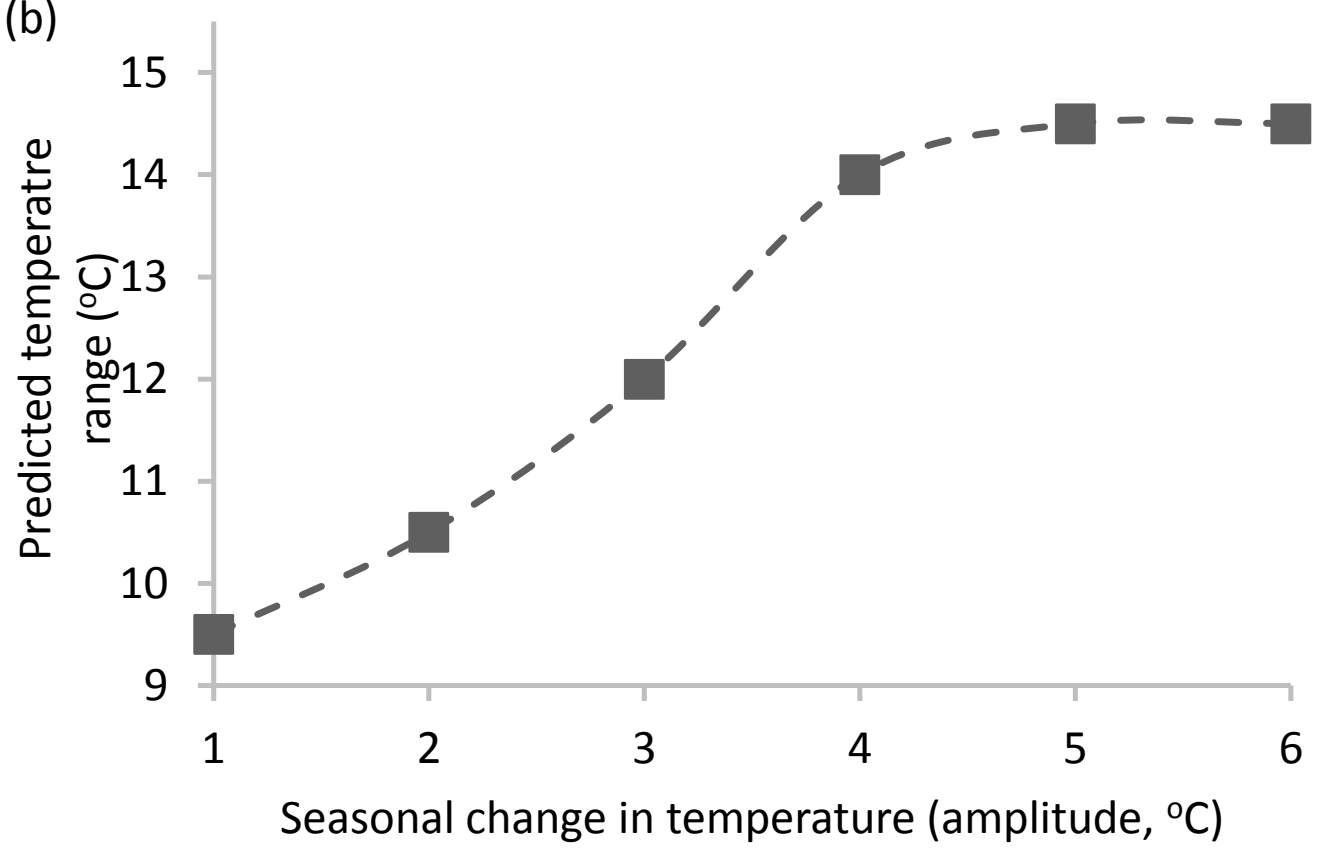

Fig. 3: (a) Predicted rate of population expansion (log increase in annual recruitment) for $U$. pinnatifida populations in response to mean annual sea water temperature. Two scenarios are represented where the seasonal change in water temperature is varied (amplitude $=3.5 \& 5.5^{\circ} \mathrm{C}$ respectively). Vertical dashed lines represent current known mean temperature distribution limits for U. pinnatifida globally: minimum $9.5^{\circ} \mathrm{C}\left(\mathrm{amp} 3.5^{\circ} \mathrm{C}\right.$ ) and maximum $22.4^{\circ} \mathrm{C}$ (amp $5.6^{\circ} \mathrm{C}$ ) (Dellatorre et al. 2014). In comparison, the model predicted temperature range for U. pinnatifida (with 
584 amplitude $=3.5 \& 5.5^{\circ} \mathrm{C}$ respectively) is $9.1-22.5^{\circ} \mathrm{C}$. (b) Change in predicted temperature range

585 (difference between $\min$ and $\max$ temperature limits) for $U$. pinnatifida in response to the 586 amplitude of the seasonal variation in sea water temperature $\left({ }^{\circ} \mathrm{C}\right)$. 


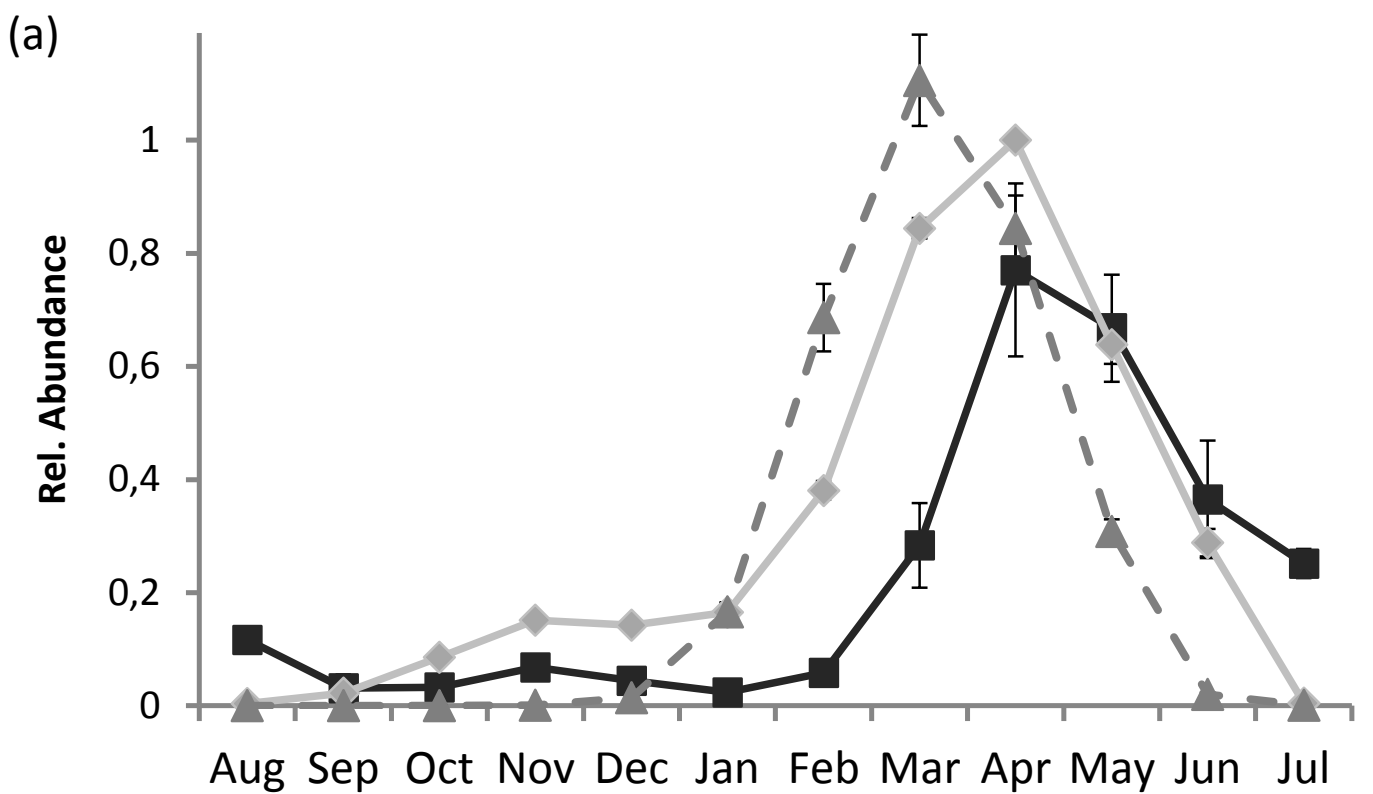

(b)

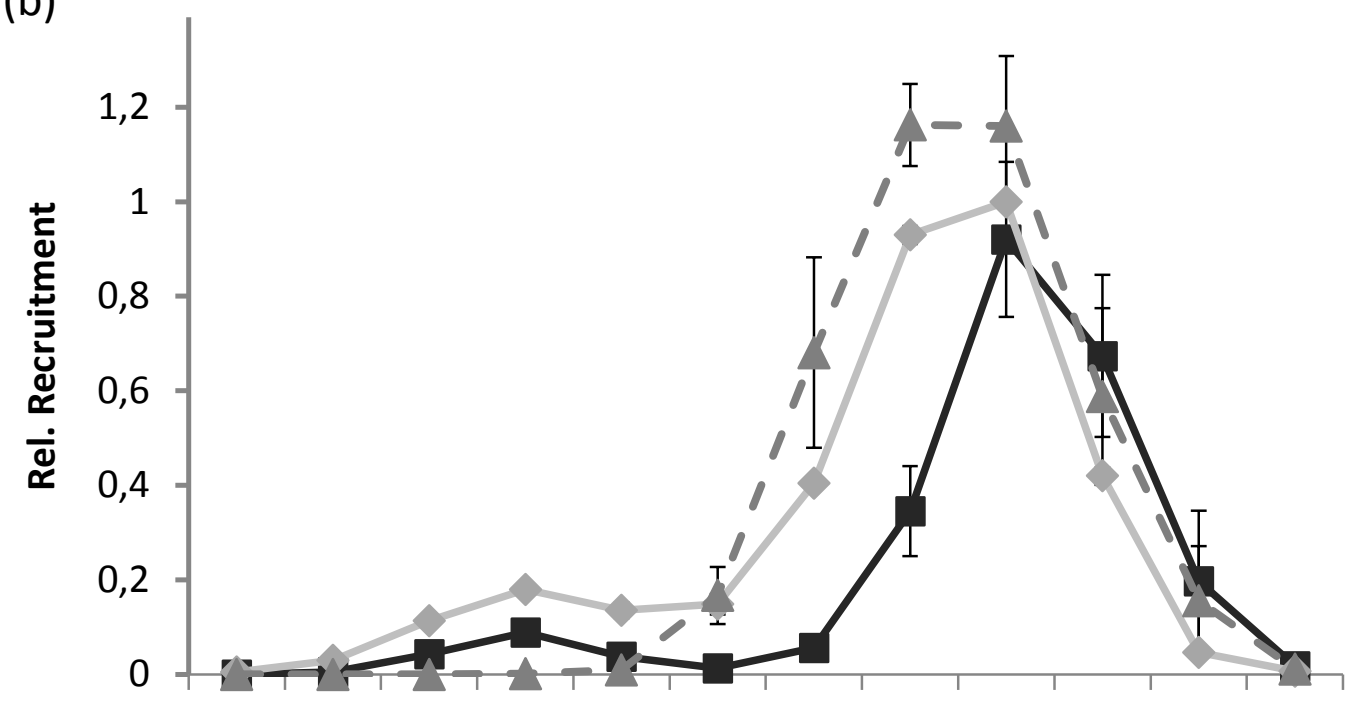

Aug Sep Oct Nov Dec Jan Feb Mar Apr May Jun Jul $\rightarrow-$ North $\rightarrow$ Central $-\leftarrow$ South

Fig. 4: Comparison between monthly (a) abundance and (b) recruitment levels predicted for populations of $U$. pinnatifida growing under the three test case scenarios after 5 years of population

593 growth. Monthly abundance and recruitment data represented relative to peak annual values in

594 Brest harbour, France. North $=$ N. Ireland; Brest $=$ Brest harbour, France; South $=$ Mediterranean Sea 595 (Taranto, Italy). 
(a)

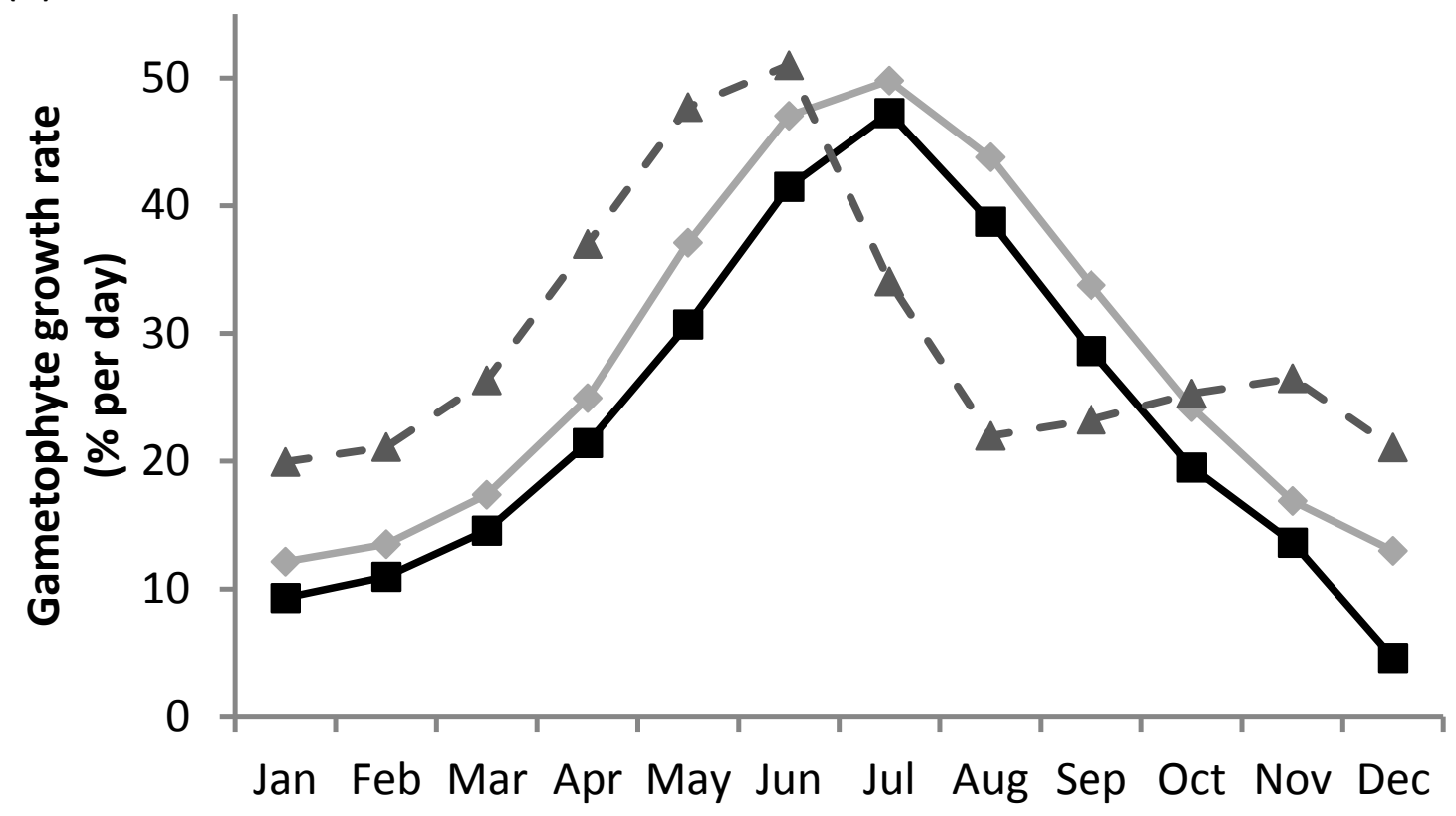

(b)

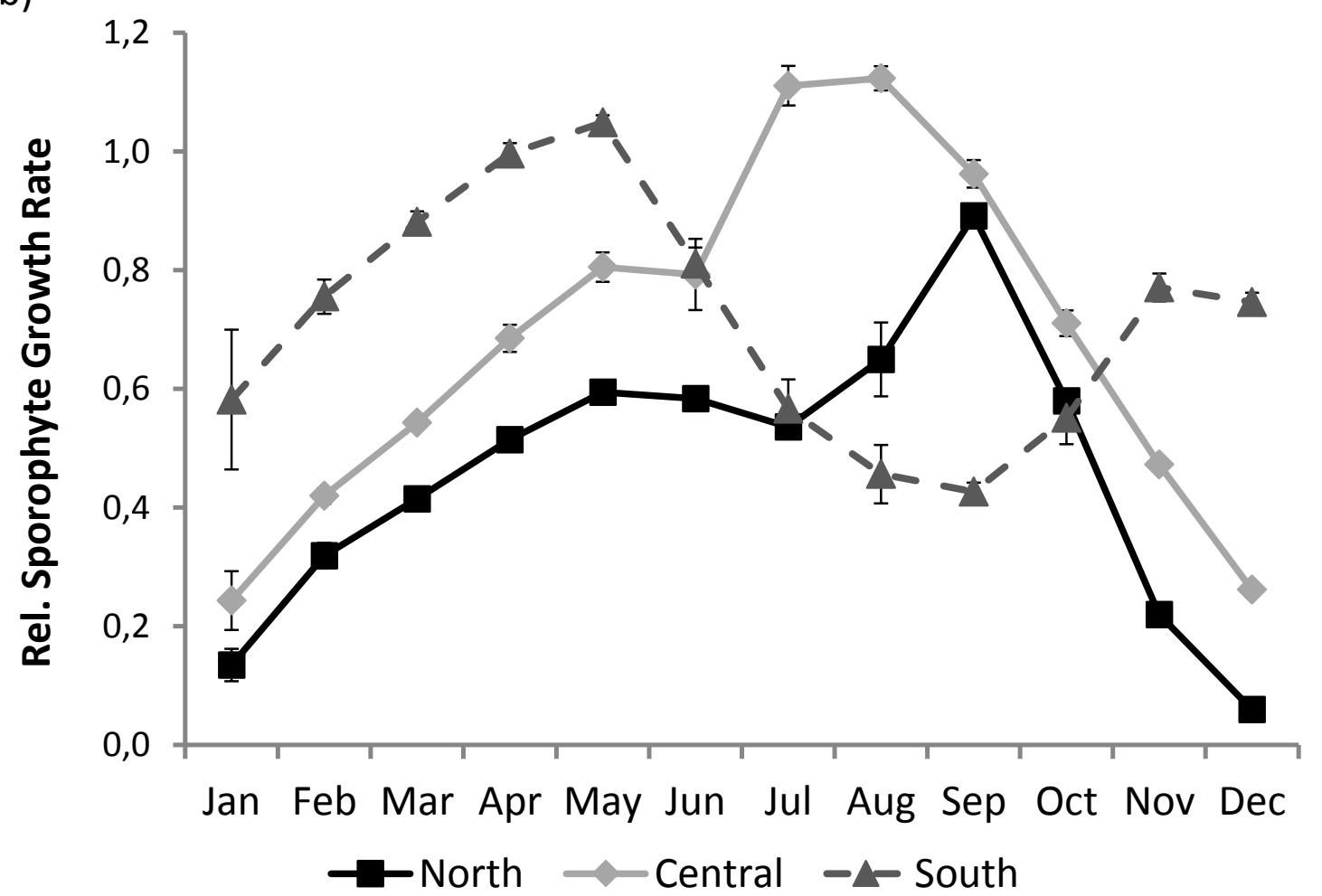

598 Fig. 5: Predicted relative growth rates of (a) gametophytes and (b) sporophytes of U. pinnatifida in 599 response to seasonal changes in temperature and day length conditions. Gametophyte growth rate 
601 temperature $=15^{\circ} \mathrm{C}$ and day length $=12$ hours. North $=$ N. Ireland; Central = Brest harbour, France;

602 South $=$ Mediterranean Sea (Taranto, Italy).

603 


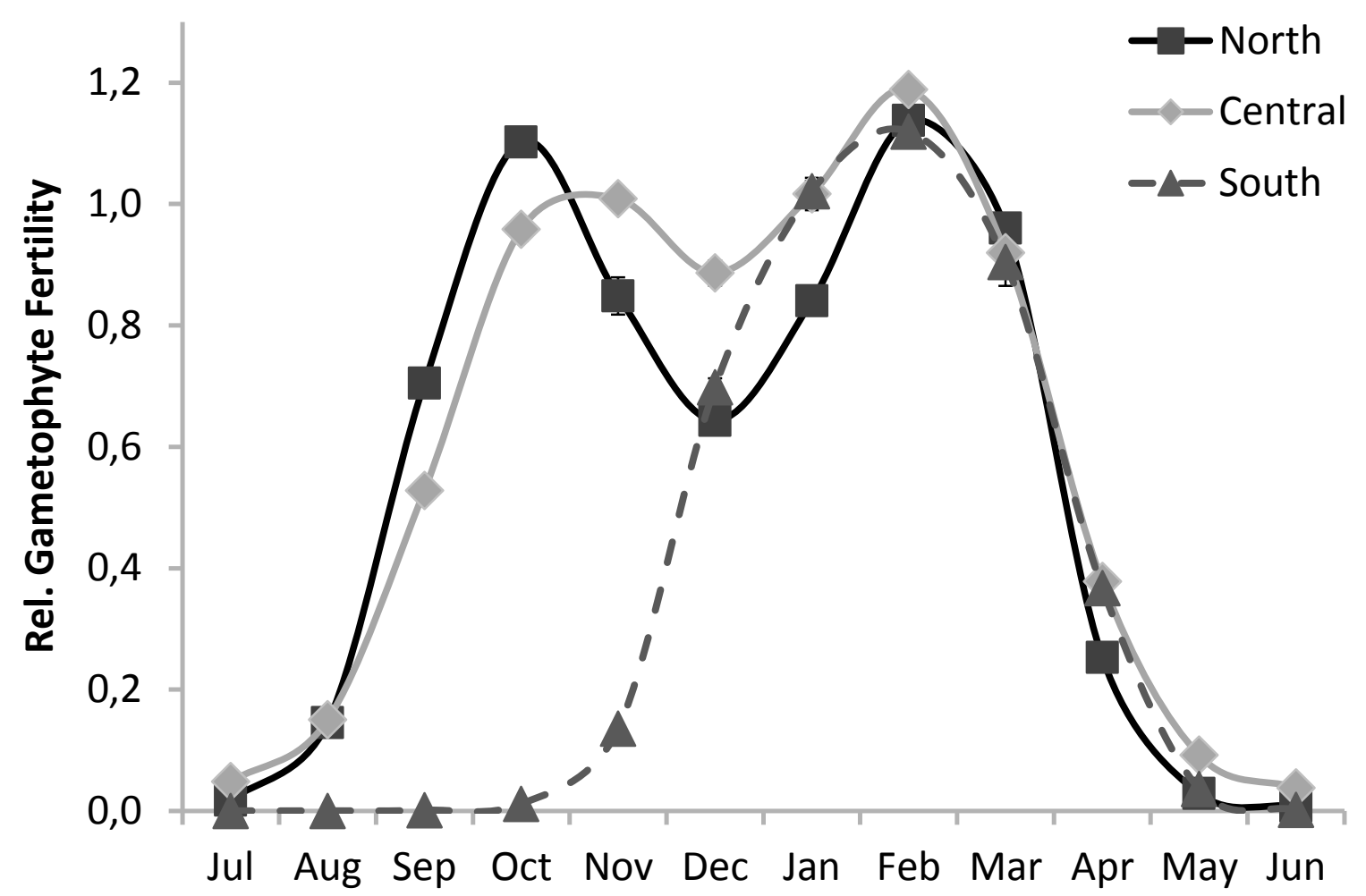

Fig. 6: Seasonal variation in predicted fertility of female gametophytes. Values expressed relative to probability of fertility when water temperature $=15^{\circ} \mathrm{C}$ and day length $=12$ hours. North $=\mathrm{N}$. Ireland; Central $=$ Brest harbour, France; South = Mediterranean Sea (Taranto, Italy). 